\title{
Mixed granulosa-Sertoli sex cord-stromal tumor of the testis: clinical, ultrasonic and histopathological features: a case report
}

\author{
Mingfang Sun, Yang Liu, Juanhan Yu, Kexin Diao, Jie Zhang, Xueshan Qiu, Xiaoyi Mi, Jian Wang \\ Department of Pathology, The First Hospital and College of Basic Medical Sciences, China Medical University, Shenyang, China \\ Correspondence to: Jian Wang. Department of Pathology, The First Hospital and College of Basic Medical Sciences, China Medical University, \\ Shenyang, China. Email: jianwang@cmu.edu.cn.
}

\begin{abstract}
Testicular sex cord-stromal tumors are less common in men, while mixed sex cord-stromal tumors (MSCSTs) are rarer. Recently, we found a MSCST in an adult male testis [adult granulosa cell tumor (AGCT) with Sertoli cell tumor]. He was admitted to the hospital based on "left testicular bloating and dull pain for 20 years and aggravating for 10 days". Routine examination of color Doppler ultrasound showed a size of approximately $1.09 \mathrm{~cm} \times 0.79 \mathrm{~cm}$ in the left testis with a low echo area, clear outline, and color flow in it. The patient underwent a radical left orchiectomy to remove the tumor. Pathological results showed that the tumor was diagnosed as testicular MSCST (AGCT with Sertoli cell tumor). He was in good health after the operation and showed no signs of recurrence or metastasis after 6 months of follow-up. We summarized the clinical, ultrasonic, and histopathological characteristics of this case. And immunohistochemical staining was very important in the pathological diagnosis of testicular MSCSTs, which can distinguish different tumor types. MSCSTs were usually mixed Sertoli-Leydig cell tumors, while this case is a MSCST of AGCT with Sertoli cell tumor, which is unique from other cases. Moreover, in this case, the doctors could not clearly diagnose the tumor through pre-operative physical, ultrasonic and laboratory examinations until the postoperative pathological examination. This further reflected the importance of pathological examination in the diagnosis of such tumors.
\end{abstract}

Keywords: Adult granulosa cell tumor (AGCT); mixed sex cord-stromal tumor (MSCST); Sertoli cell tumor; testis neoplasms; case report

Submitted Mar 22, 2020. Accepted for publication Oct 06, 2020.

doi: $10.21037 /$ tau-20-795

View this article at: http://dx.doi.org/10.21037/tau-20-795

\section{Introduction}

Most male testicular tumors are mainly germ cell tumors $(1,2)$. The incidence of sex cord-stromal tumors is low, accounting for about $4-6 \%$ of all testicular tumors $(3,4)$. Mixed sex cord-stromal tumors (MSCSTs) are rarer, currently only four cases of mixed adult granulosa cell tumor (AGCT) with Sertoli cell tumor have been reported in the literature (3,5-7). This article summarizes the clinical, ultrasonic and histopathological features of this case. We present the following case in accordance with the CARE Guideline (8) (available at http://dx.doi.org/10.21037/tau20-795).

\section{Case presentation}

\section{Medical bistory}

A 49-year-old man was admitted to the hospital with "left testicular bloating and dull pain for 20 years, aggravating for 10 days". Twenty years ago, the patient had no obvious incentive to develop discomfort and dull pain in the left testis, which can be relieved after rest, but no relief after application of anti-inflammatory drugs. After that, the above symptoms persisted and did not change significantly. Symptoms have worsened in the past 10 days. The patient denied other medical histories. He came to the hospital for further systematic diagnosis and treatment. 

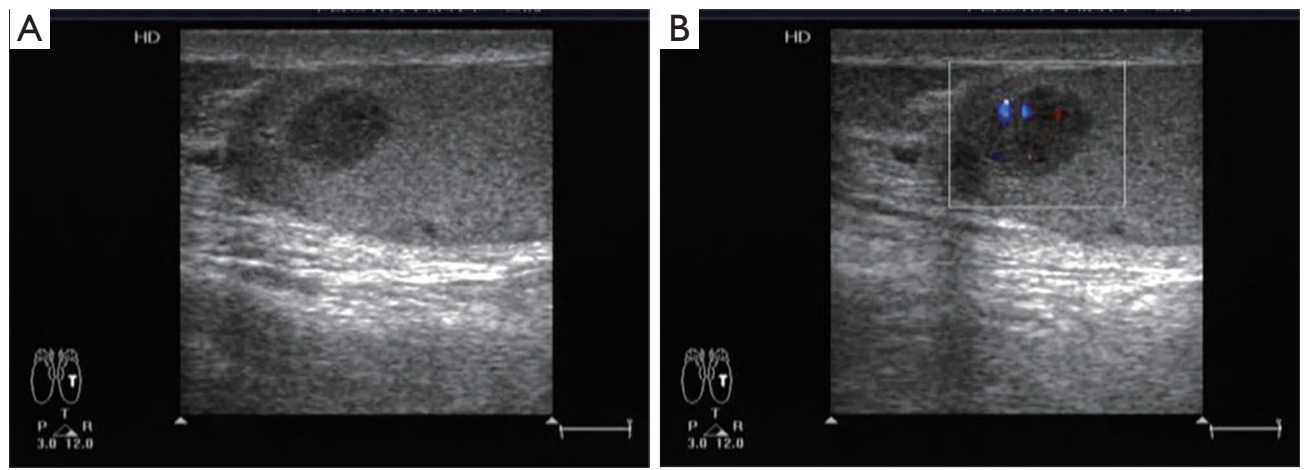

Figure 1 Ultrasound images of this case. Ultrasound revealed a $1.09 \mathrm{~cm} \times 0.79 \mathrm{~cm}$ low echo with clear outline in the left testis (A), and colorful blood flow can be seen inside (B).

\section{Physical examination}

Physical examination revealed that the left testis was palpable, enlarged compared to the contralateral testis, hard in texture, obvious in weight, smooth in the surface, no abnormal nodules were touched, no obvious tenderness, and negative in light transmission test. The size of the contralateral testis was normal. The bilateral epididymis and vas deferens were no abnormalities.

\section{Ultrasonic and laboratory examinations}

Scrotal color Doppler ultrasound (Figure 1): the sizes of both testes and epididymides were normal, the outlines were regular and neat, the internal echoes were fine and uniform, and color flow signals could be seen in both testes. The bilateral spermatic veins were not widened. Anechoic areas were seen in both epididymides, the largest one was about $0.67 \mathrm{~cm} \times 0.46 \mathrm{~cm}$. There was a $1.09 \mathrm{~cm} \times 0.79 \mathrm{~cm}$ low echo with clear outline in the left testis, and color flow signals can be seen inside. And there was an anechoic area in the left scrotum with a depth of about $0.63 \mathrm{~cm}$. Examination opinions: a space-occupying lesion in the left testis, cysts in the epididymis, and left testicular hydrocele. Laboratory results revealed the serum carbohydrate antigen 19-9 (CA19-9) was $57.5 \mathrm{U} / \mathrm{mL}$ (normal <27 U/mL), and other markers were normal.

\section{Treatment and outcome}

Based on the results of imaging and laboratory examinations, the tumor was diagnosed as a testicular tumor, and seminoma was highly likely. A radical left orchiectomy was performed on this patient. The patient recovered well after surgery and discharged with the consent of the attending physician. He had not received other treatments after the operation. He was in good condition and had no evidence of recurrence or metastasis. The timeline picture was shown in Figure 2.

\section{Postoperative pathological examination}

Grossly, the tumor was located in the left testis with clear boundaries. The size of the tumor was about $1.0 \mathrm{~cm} \times 0.7 \mathrm{~cm}$. The cut surface was tan-white, and the texture was medium.

Histologically, the tumor was composed of two components, $90 \%$ were AGCTs and $10 \%$ were Sertoli cell tumors (Figure 3). In the AGCT areas, the tumor cells were densely arranged in diffuse or island shapes, and CallExner-like structures could be seen locally. The cytoplasm was lightly stained, and some nuclei were pale and groundglass-like with grooves, and no necrosis and pathological mitotic figures were seen. The tumor cells in the Sertoli cell tumor areas were tubular differentiated. And the cells were more uniform in size with less cytoplasm and deep nuclear staining. Obvious fibrous components were found in the stroma, and normal intrinsic seminiferous tubules and germ cells could be found.

Immunohistochemistry showed both Sertoli cells and granulosa cells were positive for vimentin, while WT1 was positive and weakly positive, respectively. In addition, Sertoli cells were positive for cytokeratin (CK) and granulosa cells were positive for inhibin- $\alpha$, S-100, CD99. All tumor cells and stromal cells were negative for CD117, alpha-fetoprotein (AFP), human chorionic gonadotrophin (HCG), POU class 5 homeobox 1 (OCT3/4), spalt like transcription factor 4 (SALL4) and placental alkaline 


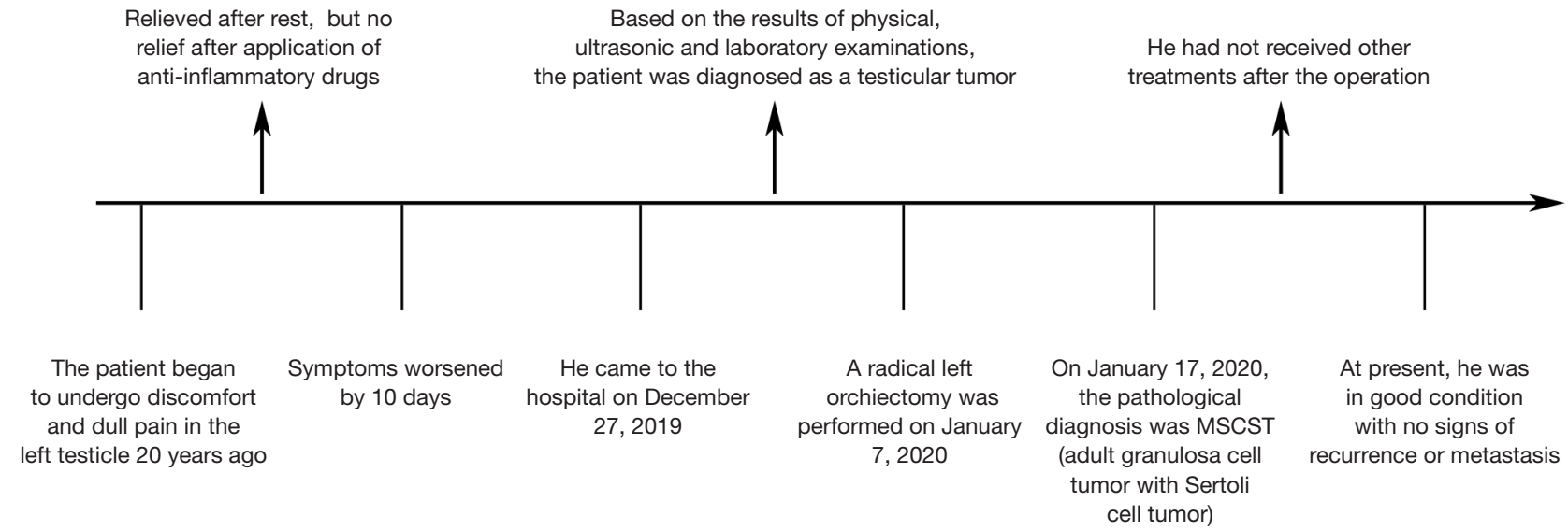

Figure 2 The timeline picture of this case.
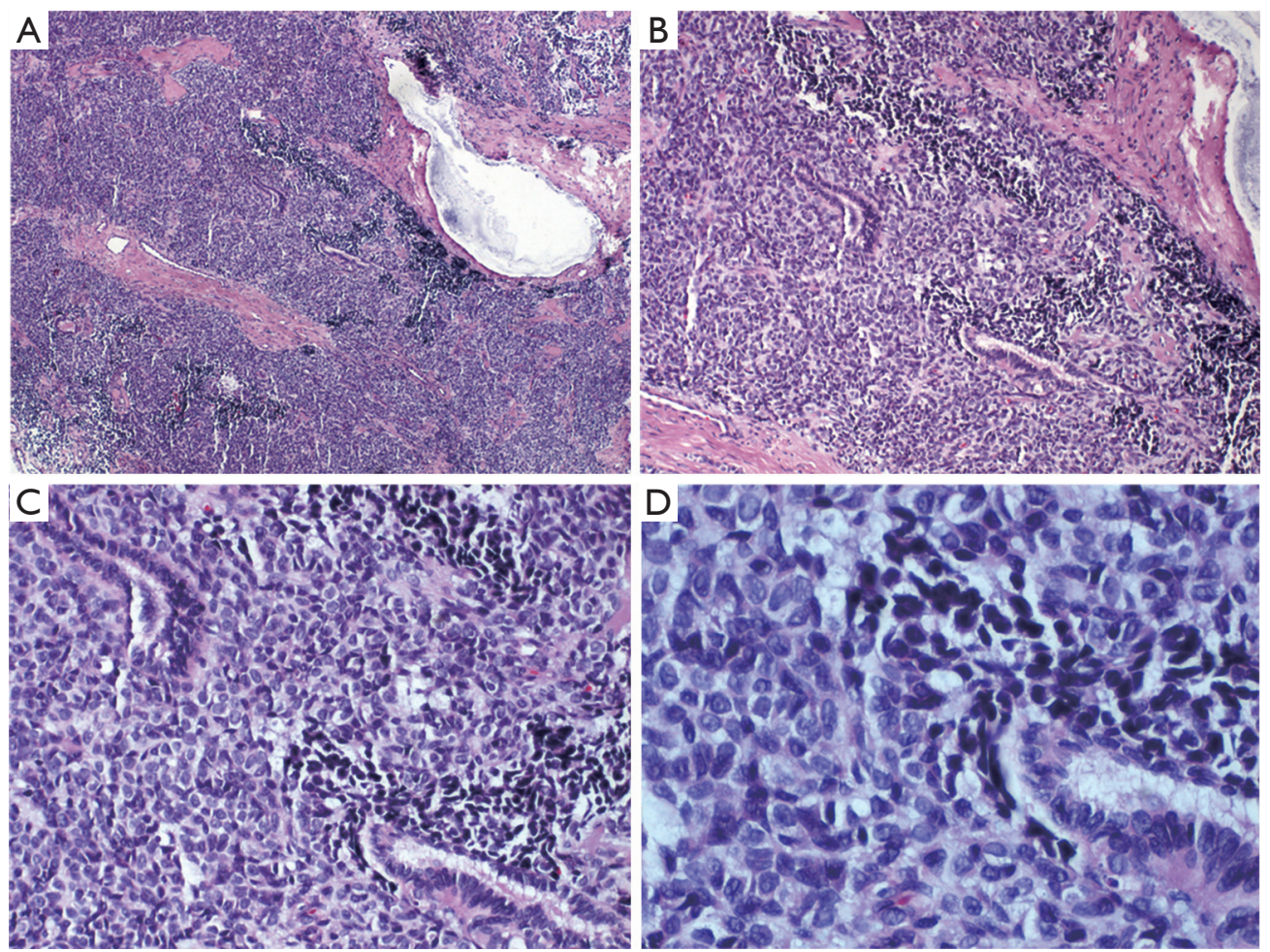

Figure 3 Morphological characteristics of this tumor. The tumor was composed of two components, $90 \%$ were AGCTs and $10 \%$ were Sertoli cell tumors. H\&E staining, A ×40, B ×100, C ×200, D ×400. AGCTs, adult granulosa cell tumors.

phosphatase (PLAP) (Figure 4).

The postoperative pathological diagnosis was MSCST (AGCT with Sertoli cell tumor). The prognosis of this tumor is low-grade malignant tumor, with a certain risk of recurrence and metastasis.
All procedures performed in studies involving human participants were in accordance with the ethical standards of the institutional and/or national research committee(s) and with the Helsinki Declaration (as revised in 2013). Written informed consent was obtained from the patient. 

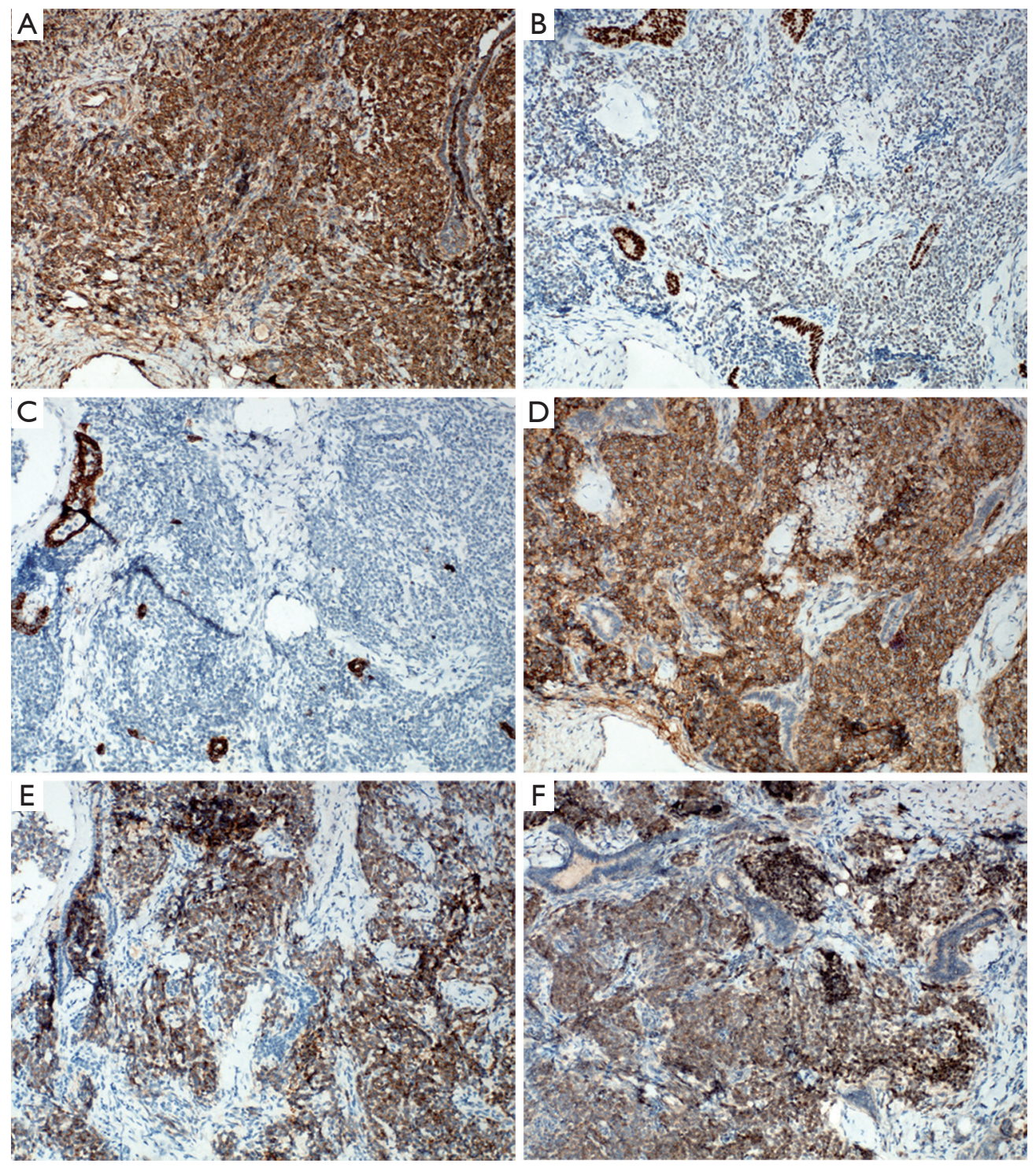

Figure 4 Immunohistochemical staining of this tumor. Both Sertoli cells and granulosa cells were positive for vimentin (A). WT1 was positive in Sertoli cells and weakly positive in granulosa cells (B). Sertoli cells were positive for CK (C). Granulosa cells were positive for CD99 (D), inhibin- $\alpha$ (E) and S-100 (F). S-P immunohistochemical method, $\times 100$.

\section{Discussion and differential diagnoses}

According to the patient's clinical information, ultrasonic features, histological features and immunohistochemical staining, the tumor was diagnosed as MSCST. Sex cordstromal tumors mainly include Leydig cell tumors, Sertoli cell tumors, granulosa cell tumors, and also include mixed forms (which can be composed of any of the above types) and incompletely differentiated tumors (7). In the WHO classification 2016 of testicular non-germ cell tumors, the subgroups of "mixed" and "incompletely differentiated" forms of sex cord-stromal tumors have been replaced by "mixed and unclassified sex cord-stromal tumors" (9). MSCSTs refer to tumors containing two or more sex cord-stromal components. The incidence is extremely rare. They often occur in middle-aged and elderly men and show swelling or masses of testes. However, the immunohistochemical characteristics of each component of the tumors are consistent with their tumor types, which can help to identify. In addition, reticular fiber staining can also 
help define the diagnosis.

\section{Differential diagnoses}

\section{Gonadoblastoma}

Gonadoblastomas consist of two cell types: germ cells [which can be similar to germ cell neoplasia in situ (GCNIS) cells] and sex cord cells similar to immature granulosa cells. The tumor cells of gonadoblastomas are often scattered in nests, with eosinophilic basement membrane material (10). GCNIS-like cells have clear cytoplasm and polygonal nuclei, with one or more prominent nucleoli. Other germ cells may have the morphological characteristics of spermatogonia, with less cytoplasm, granular chromatin, and insignificant nucleoli. Immunohistochemical results are often positive for PLAP, OCT3/4, and SALL-4. The sex cord cells have angulated nuclei with little cytoplasm, which can be nested, or surrounded by basement membrane deposits (Call-Exner-like pattern) or arranged around germ cells. Common positive immunohistochemical markers are WT1, inhibin- $\alpha$ and CD99.

\section{Endometrioid carcinoma with cord-like differentiation}

Ovarian epithelial-type tumors can also occur in the testes, such as serous cancer, mucinous cancer, and endometrioid cancer (11-13). Morphologically, poorly differentiated endometrioid carcinoma with sex cord-like regions can lead to confusion with sex cord-stromal tumors. Tumor cells in the poorly differentiated solid areas of endometrioid carcinoma may have pale nuclei, or even nuclear grooves, which are sometimes indistinguishable from adult type granulosa cell tumors. Occasionally, histological structures are also similar to adult type granulosa cell tumors, such as diffuse, solitary or trabecular, and even microfollicular patterns. The presence of typical endometrioid carcinoma, squamous differentiation can help diagnose endometrioid carcinoma. The cytokeratin 7 (CK7), epithelial membrane antigen (EMA) positive and inhibin-a, calretinin, WT1 negative immunostaining pattern is more supported an endometrioid carcinoma. In addition, reticular fiber staining can also help with identification.

\section{Mixed Sertoli-Leydig cell tumor}

Tumors are composed of Sertoli cells and Leydig cells in different proportions. There may be primitive gonadstromal components and sometimes heterogeneous components in the medium-differentiated and poorly- differentiated tumors. It is described in detail in the WHO classification of tumors of female reproductive organs, and reported cases of testis are extremely rare (14). Sertoli cells form hollow or solid tubules and lack significant nuclear atypia or mitotic activity. There is a delicate fibrous stroma in which eosinophil-rich cytoplasmic Leydig cells are arranged in tubules, cords, and singly. Reinke crystals in the cytoplasm can be clearly confirmed. However, when Leydig cells are few or atypical, they are sometimes difficult to identify, making diagnosis difficult. Differences in immunophenotypes can help identify the individual components. Vimentin, CK, inhibin- $\alpha$, and calretinin are positive, but the intensity of expression is different between Sertoli cell and Leydig cell areas. In addition, Sertoli cells are positive for CD56, steroidogenic factor-1 (SF-1), and WT-1, while Leydig cells tend to be negative, but express melan-A.

The MSCST (AGCT with Sertoli cell tumor) reported in this case is very rare. It is difficult to diagnose from the clinical and ultrasound features. Although there are certain morphological characteristics, the mixed components are not easy to identify. Therefore, immunohistochemistry is very important for diagnosis. However, it should be noted that the specificity and sensitivity of some tumor cells are not strong, which may bring some difficulties to diagnose. In addition, due to the relatively short follow-up time of this case and the rarity of such cases, it may not provide clinicians with sufficient information and experience.

\section{Conclusions}

Although testicular MSCSTs have a very low incidence, they should be considered in the differential diagnosis of adult testicular tumors, but the diagnosis may be challenging. This case provided the clinical, ultrasonic and pathological characteristics of MSCSTs (AGCT with Sertoli cell tumor), and provided some help for the diagnosis of testicular MSCSTs. Our experience showed that immunohistochemical staining played a crucial role in the diagnosis of MSCSTs because this method can distinguish different tumor types.

\section{Acknowledgments}

Funding: This study was supported by Natural Science Foundation of Liaoning Province (Grant No. 201602859 to JW). 


\section{Footnote}

Reporting Checklist: The authors have completed the CARE reporting checklist. Available at http://dx.doi.org/10.21037/ tau-20-795

Conflicts of Interest: All authors have completed the ICMJE uniform disclosure form (available at http://dx.doi. org/10.21037/tau-20-795). The authors have no conflicts of interest to declare.

Ethical Statement: The authors are accountable for all aspects of the work in ensuring that questions related to the accuracy or integrity of any part of the work are appropriately investigated and resolved. All procedures performed in studies involving human participants were in accordance with the ethical standards of the institutional and/or national research committee(s) and with the Helsinki Declaration (as revised in 2013). Written informed consent was obtained from the patient.

Open Access Statement: This is an Open Access article distributed in accordance with the Creative Commons Attribution-NonCommercial-NoDerivs 4.0 International License (CC BY-NC-ND 4.0), which permits the noncommercial replication and distribution of the article with the strict proviso that no changes or edits are made and the original work is properly cited (including links to both the formal publication through the relevant DOI and the license). See: https://creativecommons.org/licenses/by-nc-nd/4.0/.

\section{References}

1. Woodward PJ, Sohaey R, O'Donoghue MJ, et al. From the archives of the AFIP: tumors and tumorlike lesions of the testis: radiologic-pathologic correlation. Radiographics 2002;22:189-216.

2. Albers $\mathrm{P}$, Albrecht $\mathrm{W}$, Algaba F, et al. EAU guidelines on testicular cancer: 2011 update. European Association of Urology. Actas Urol Esp 2012;36:127-45.

Cite this article as: Sun M, Liu Y, Yu J, Diao K, Zhang J, Qiu $\mathrm{X}$, Mi X, Wang J. Mixed granulosa-Sertoli sex cord-stromal tumor of the testis: clinical, ultrasonic and histopathological features: a case report. Transl Androl Urol 2020;9(6):2836-2841. doi: $10.21037 /$ tau-20-795
3. Allen DC, Moorehead RJ. Mixed sex-cord stromal tumour of the testis. Ulster Med J 1997;66:54-6.

4. Brekelbaum CE, Abreo F, Fowler M, et al. Undifferentiated sex cord/stromal testis tumor. Urology 2000;55:436.

5. el Khader K, Ouali M, Mahassini N, et al. Unusual testicular tumor: Leydig, Sertoli, and granulosa cell mixed tumor. Prog Urol 2001;11:82-5.

6. Eble JN, Hull MT, Warfel KA, et al. Malignant sex cordstromal tumor of testis. J Urol 1984;131:546-50.

7. Tahaineh S, Mughli RA, Fallatah M. Giant mixed SertoliLeydig-Granulosa sex cord tumor of the testis; clinical, histopathological, and radiological features: a case report. Pan Afr Med J 2017;27:51.

8. Riley DS, Barber MS, Kienle GS, et al. CARE guidelines for case reports: explanation and elaboration document. J Clin Epidemiol 2017;89:218-35.

9. Idrees MT, Ulbright TM, Oliva E, et al. The World Health Organization 2016 classification of testicular non-germ cell tumours: a review and update from the International Society of Urological Pathology Testis Consultation Panel. Histopathology 2017;70:513-21.

10. Kao CS, Ulbright TM, Idrees MT. Gonadoblastoma: an immunohistochemical study and comparison to Sertoli cell nodule with intratubular germ cell neoplasia, with pathogenetic implications. Histopathology 2014;65:861-7.

11. Jones MA, Young RH, Srigley JR, et al. Paratesticular serous papillary carcinoma. A report of six cases. Am J Surg Pathol 1995;19:1359-65.

12. Nistal M, Revestido R, Paniagua R. Bilateral mucinous cystadenocarcinoma of the testis and epididymis. Arch Pathol Lab Med 1992;116:1360-3.

13. Young RH, Scully RE. Testicular and paratesticular tumors and tumor-like lesions of ovarian common epithelial and müllerian types. A report of four cases and review of the literature. Am J Clin Pathol 1986;86:146-52.

14. Tazi MF, Ahallal Y, Khallouk A, et al. Concomitant sertoli and leydig cell tumor of the testis: a case report. Rev Urol 2011;13:173-5. 